\title{
Puerperal sepsis and its associated factors among mothers in University of Gondar referral hospital, Ethiopia, 2017
}

\begin{abstract}
Background: puerperal sepsis is infection of the genital tract occurring at any time after 24 hour of delivery up to the $42^{\text {nd }}$ days of postpartum. Globally 6 million had developed puerperal sepsis and around 77,000 mothers died of it. It is one of the fifth common cause of maternal mortality worldwide. However there were limited evidences on factors affecting the occurrence of puerperal sepsis in Ethiopia generally and in the study area particularly.

Objective: To assess prevalence of puerperal sepsis and associated factors among mothers who utilize postnatal care at University of Gondar referral hospital, North West Ethiopia, 2017

Method: An institutional based quantitative cross sectional study was conducted among postnatal women from $1^{\text {st }}$ september $-30^{\text {th }}$ December, 2017. Simple random sampling technique was used to select study participants. A pre-tested semi structured questionnaire was used to collect data from 219 women who utilize postnatal care service in Gondar University Hospital from $1^{\text {st }}$ september $-30^{\text {th }}$ December, 2017. Data were entered into EPI info version 7 and analyzed using SPSS version 20 software. Bivariate and multivariable logistic regression model was fitted to identify factors associated with occurrence of puerperal sepsis. Odds ratio with $95 \%$ confidence interval was computed to determine the level of significance.
\end{abstract}

Result: The occurrence of puerperal sepsis in the study area was found to be $17.2 \%$, ( $95 \% \mathrm{CI} 12.0-22.5)$. Having cesarean section delivery ( $\mathrm{AOR}=.3895 \% \mathrm{CI}$ (.18-.81), being primiparous and multiparas $(\mathrm{AOR}=3.92(1.10-13.92)$ were factors found to be associated with puerperal sepsis

Conclusion: The prevalence of puerperal sepsis in the postnatal clinic of university of Gondar was found to be high. PROM, Mode of delivery, parity and mode of placental removal were factors found to be associated with puerperal sepsis.

Keywords: puerperal sepsis, postnatal, primiparous, maternal death
Volume 5 Issue 5 - 2019

\author{
Daniel Atlaw,' Kenbon seyoum, ${ }^{2}$ Demelash \\ Woldeyohannes, ${ }^{3}$ Marta Berta ${ }^{4}$ \\ 'Department of Human Anatomy, Madda Walabu University \\ Goba Referral Hospital, Ethiopia \\ ${ }^{2}$ Department of midwifery, Madda Walabu University Goba \\ Referral Hospital, Ethiopia \\ ${ }^{3}$ Department of public health, Madda Walabu University Goba \\ Referral Hospital, Ethiopia \\ ${ }^{4}$ Department of midwifery, University of Gondar College of \\ Medicine and Health Science, Ethiopia
}

Correspondence: Daniel Atlaw, Department of Human Anatomy, Madda Walabu University Goba Referral Hospital, Ethiopia, Email danielatmwu@gmail.com

Received: July 23, 2019 | Published: October 30, 2019
Abbreviations: ANC, antenatal care; AOR, adjusted odds ratios; CI, confidence interval; $\mathrm{C} / \mathrm{s}$ - cesarean section; $\mathrm{OR}$, crudes odds ratios; MDGs, millennium development goals; OR, odds ratio; PS-puerperal sepsis PROM-premature rupture of membrane; UoGUniversity of Gondar; WHO-world health organization.

\section{Background}

Puerperal sepsis is infection of the genital tract occurring at any time between the rupture of membranes or labor, and the $42^{\text {nd }}$ days of postpartum). ${ }^{1}$ The risk of a woman in a developing country dying from a maternal-related cause during her lifetime is about 33 times higher compared to a woman living in a developed country. ${ }^{2}$ Sepsis causes $10.7 \%$ of maternal deaths worldwide. Mothers living in developed countries die from sepsis less than those in developing countries. It causes more death in Asian countries, Caucasus, Latin America, Caribbean, Oceania, north Africa and sub-Saharan Africans. ${ }^{3}$

Seventy seven thousand mothers die of puerperal sepsis from the total of 6 million global cases of puerperal sepsis. ${ }^{4}$ Another study showed that 75000 maternal deaths occur every year due to puerperal sepsis and most of this deaths occur in low income countries. ${ }^{5}$

Puerperal sepsis is one of the major causes of maternal death and accounts for 15 per cent of all maternal deaths in developing countries. If it does not cause death, puerperal sepsis can cause long-term health problems such as chronic pelvic inflammatory disease (PID) and infertility. ${ }^{6}$ Puerperal sepsis is the fourth common cause of maternal mortality after postpartum bleeding, unsafe abortion and hypertensive disorder of pregnancy. It causes about $8 \%$ of maternal deaths. ${ }^{7}$ According to the report of Borgen project puerperal sepsis is the fourth leading cause of maternal death in Ethiopia. ${ }^{8}$ Pelvic inflammatory disease and puerperal sepsis (PS) are the major causes of gynecologic morbidity at St. Paul's Hospital, Addis Ababa. ${ }^{9}$ This study revealed the magnitude of puerperal sepsis and socio-demographic, obstetric, individual and medical factors associated with it among postnatal care utilizing mothers in the study area.

\section{Methods}

An institution based cross-sectional study design was conducted in postnatal clinic of university of Gondar (UoG) referral hospital. 
University of Gondar Hospital is referral center for four district hospitals in the area. It has a range of specialties including pediatrics, surgery, gynecology, psychiatry, HIV care and an outpatient's clinic. It is one of the five referral hospital in the Amhara region. The hospital provide service to four million people and has 6 wards. The obstetrics and gynecology ward provide all maternal and reproductive health service including postnatal service. The study period was from September 1 to December 30/2017. All mothers who came for postnatal care service at UoG referral hospital were the source population

Inclusion criteria: all postpartum mothers who visited postnatal clinic of UoG referral hospital during data collection period.

Exclusion criteria: mothers who were severely ill and unable to communicate throughout the data collection period were the exclusion criteria.

\section{Sample size and sampling procedures}

Sample size was calculated using sample size for single population proportion formula by considering the assumptions of $16.2 \%$ proportion, $95 \% \mathrm{CI}$, $5 \%$ degree of precision. Simple random sampling technique was used to recruit study participants. Per a month an average of 109 clients visit postnatal clinic of UoG referral hospital. Around 436 postnatal mothers visit the clinic for the duration of the study period. So by dividing 436 for 219 we found the $\mathrm{k}^{\text {th }}$ value of 2. The data was obtained from the postnatal clinic monthly report Information was collected from every second mother visiting the clinic. The mothers were informed not to give information twice if they come again during data collection period.

\section{Study variables}

Puerperal sepsis is dependent variable while sociodemographic factors such as (Age, place of residence, maternal educational status, occupational status, marital status, religion, husband educational status), Obstetric characteristic variables (parity, number of ANC visit, onset of labour, mode of delivery, place of delivery, premature rapture of membrane, prolonged labour), individual factors (ANC, bathing days, home deliveries, deliveries conducted by TBA), medical factors(HIV'/AIDS, Preeclampsia/ eclampsia, Diabetes status, anemia) are explanatory variables included in the study.

\section{Operational definitions}

Puerperal sepsis: infection of the genital tract occurring at any time between $24 \mathrm{hr}$ after delivery and the $42^{\text {nd }}$ days of postpartum in which 2 or more of the following signs and symptoms are present: Pelvic pain, Fever i.e. temperature of $38^{\circ} \mathrm{C}$ or higher on any occasion, foul smelling vaginal discharge, delay in the rate of reduction of the size of the uterus $(<2 \mathrm{~cm} /$ day during the first 8 days $)$.

\section{Data collection procedures and data quality assurance}

Structured interviewer administered questionnaire, secondary data and physical examination was used to obtain information on sociodemographic, obstetric, medical and individual factors about prevalence and associated factors of puerperal sepsis. Before starting the actual survey data was pretested. Through the course of data collection the data collectors were supervised and there was regular phone contact between principal investigator and supervisor to discuss and to correct problem which was raised during data collection period. Every two weeks the collected questionnaires were reviewed by supervisors to check for completeness. Incomplete data's were discarded and considered as non-response. Finally the collected data was reviewed and checked for full completeness before data entry.

\section{Data processing and analysis}

The collected questionnaires was coded and entered into Epi Info ${ }^{\mathrm{TM}}$ version 7. After the entry was completed the data was exported to SPSS version 20.0 and cleaned before analysis. Descriptive and summary statistics was done. Bivariate logistic regression analysis was used to determine the association of each independent variable with the outcome variable. Variables significant in bivariate analysis $(\mathrm{P}<$ 0.2 ) was entered into a multivariate logistic regression model to adjust the effects of possible cofounders on the outcome variable. HosmerLemeshow goodness of fit was used to check the model fitting. Odds ratio (OR) with $95 \%$ confidence interval (CI) was computed to see the association between independent variables and dependent variable. $\mathrm{P}$-value of less than 0.05 was used to declare association.

\section{Ethical considerations}

To conduct this research project, ethical approval was obtained from the ethical review committee of Department of Midwifery, College of Medicine and Health Sciences, University of Gondar. Next, Official letters was submitted to CEO of the Hospital and to the head of the ward. Permission was obtained from the head of the ward and from each study subjects prior to the data collection process. Each respondent was informed about the aim of the study. They were also informed that all data obtained from them will be kept confidential by using codes instead of any personal identifiers and is meant only for the purpose of the study.

\section{Result}

A total of 219 study participants participated in this study yielding a response rate of $96 \%$. The remaining $4 \%$ non-responses were due to incomplete data.

\section{Sociodemographic variables of the respondent}

A total of 219 study participants participated in this study yielding a response rate of $96 \%$. This non response rate is because of incomplete data's not due to sensitivity issue. $45.5 \%$ of the study participants were in the age group of 25-29. The mean age of the study subjects was 27.31 , standard deviation is 4.66 and the range was 22 years (Table 1).

Table I Socio-demographic characteristics of study participants utilizing postnatal care service at university of Gondar referral hospital, North West Ethiopia 2017, N=209

\begin{tabular}{lll}
\hline Variable & Frequency & $\%$ \\
\hline Age & 51 & \\
$18-24$ & 95 & 24.4 \\
$25-29$ & 44 & 45.5 \\
$30-34$ & 19 & 21 \\
$>=35$ & & 9.1 \\
Ethnicity & & \\
\hline Variable & Frequency & $\%$ \\
\hline
\end{tabular}




\section{Table Continued}

\begin{tabular}{|c|c|c|}
\hline Amhara & 197 & 94.3 \\
\hline Kimant & 9 & 4.3 \\
\hline Tigre & 3 & $\mathrm{I} .4$ \\
\hline \multicolumn{3}{|l|}{ Marital status } \\
\hline married & 206 & 98.6 \\
\hline widowed & 3 & 1.4 \\
\hline \multicolumn{3}{|l|}{ Religion } \\
\hline Orthodox & 196 & 91.4 \\
\hline Muslim & 18 & 8.6 \\
\hline \multicolumn{3}{|l|}{ Residence } \\
\hline rural & 31 & 14.8 \\
\hline urban & 178 & 85.2 \\
\hline \multicolumn{3}{|l|}{ Education } \\
\hline Can't read and write & 32 & 15.3 \\
\hline \multicolumn{3}{|l|}{ primary } \\
\hline secondary & 59 & 28.2 \\
\hline \multirow[t]{3}{*}{ above secondary } & 71 & 34 \\
\hline & 47 & \\
\hline & & 22.5 \\
\hline \multicolumn{3}{|l|}{ Occupation } \\
\hline Government employee & 42 & 20.1 \\
\hline house wife & 104 & 49.8 \\
\hline farmer & 19 & 9.1 \\
\hline merchant & 34 & 16.3 \\
\hline student & 7 & 3.3 \\
\hline daily worker & 3 & 1.4 \\
\hline
\end{tabular}

\section{Obstetric factors affecting prevalence of puerperal} sepsis

Labor started spontaneously in $165(78.9 \%)$ of the respondents, $32(15.3 \%)$ were induced and does not started in 12(5.8\%). Labor delayed for $12-24 \mathrm{hr}$ in $117(56.1 \%)$. Out of all the study participants $48(23 \%)$ had rupture of membrane before the onset of labor. Of those who had premature rupture of membrane labour started within $12 \mathrm{hr}$ and less in $95.8 \%$ (Table 2).

Table 2 Obstetric variable among postnatal mothers utilizing postnatal care

service at university of Gondar referral hospital, North West Ethiopia 2017 $\mathrm{N}=209$

Variable $\quad$ Frequency
Referred from other
health institution
yes
no




\section{Individual factors affecting puerperal sepsis}

All of the study participants were asked whether they had birth and emergency preparation plan and about their place of delivery. $86.6 \%$ replied that they had birth and emergency preparation plan and all of them answered that they delivered at health institution and all assisted by health professionals (Table 3 ).

Table 3 Puerperal sepsis and individual factors among study participants utilizing postnatal care service at university of Gondar referral hospital, North West Ethiopia, 2017, N=209

\begin{tabular}{|c|c|c|}
\hline Variables & Frequency & $\%$ \\
\hline \multicolumn{3}{|l|}{$\begin{array}{l}\text { Birth and emergency } \\
\text { preparation plan }\end{array}$} \\
\hline \multirow[t]{2}{*}{ no } & 181 & 86.6 \\
\hline & 28 & 13.4 \\
\hline \multicolumn{3}{|l|}{ Place of delivery } \\
\hline home & 0 & 0 \\
\hline health institution & 209 & 100 \\
\hline \multicolumn{3}{|l|}{$\begin{array}{l}\text { Took shower after } \\
\text { delivery }\end{array}$} \\
\hline yes & 198 & 94.7 \\
\hline no & II & 5.3 \\
\hline \multicolumn{3}{|l|}{$\begin{array}{l}\text { Time of shower after } \\
\text { delivery }\end{array}$} \\
\hline Ist day & 55 & 27.8 \\
\hline 2nd day & 67 & 33.83 \\
\hline 3rd day & 31 & 15.65 \\
\hline after 3rd day & 45 & 22.72 \\
\hline \multicolumn{3}{|l|}{ Booked } \\
\hline yes & 208 & 99.5 \\
\hline no & I & 0.5 \\
\hline \multicolumn{3}{|l|}{ No of antenatal care } \\
\hline I & 3 & $\mathrm{I} .44$ \\
\hline 2 & 12 & 5.77 \\
\hline 3 & 62 & 29.81 \\
\hline 4 and above & $|3|$ & 62.98 \\
\hline \multicolumn{3}{|l|}{$\begin{array}{l}\text { Assisted/attended } \\
\text { during delivery }\end{array}$} \\
\hline yes & 209 & 100 \\
\hline no & 0 & 0 \\
\hline Assisted/attended by & 0 & 0 \\
\hline \multicolumn{3}{|l|}{$\begin{array}{l}\text { TBA traditional birth } \\
\text { attendants }\end{array}$} \\
\hline Health professional & 209 & 100 \\
\hline
\end{tabular}

\section{Medical characteristics of the respondents}

All of the mothers utilizing postnatal care service at the study area were asked about the status of their diabetes, HIV, and hypertension and their card were reviewed to check their HIV and hemoglobin status to identify whether they were anemic or not at the time of delivery (Table 4).
Table 4 Medical factors affecting puerperal sepsis among postnatal mothers utilizing postnatal care service at university of Gondar referral hospital, North West Ethiopia, 2017, N=209

\begin{tabular}{|c|c|c|}
\hline Variables & Frequency & $\%$ \\
\hline \multicolumn{3}{|l|}{$\begin{array}{l}\text { Birth and emergency } \\
\text { preparation plan }\end{array}$} \\
\hline \multicolumn{3}{|l|}{ yes } \\
\hline \multirow[t]{2}{*}{ no } & 181 & 86.6 \\
\hline & 28 & 13.4 \\
\hline \multicolumn{3}{|l|}{ Place of delivery } \\
\hline home & 0 & 0 \\
\hline health institution & 209 & 100 \\
\hline \multicolumn{3}{|l|}{$\begin{array}{l}\text { Took shower after } \\
\text { delivery }\end{array}$} \\
\hline yes & 198 & 94.7 \\
\hline no & II & 5.3 \\
\hline \multicolumn{3}{|l|}{$\begin{array}{l}\text { Time of shower after } \\
\text { delivery }\end{array}$} \\
\hline Ist day & 55 & 27.8 \\
\hline 2nd day & 67 & 33.83 \\
\hline 3rd day & 31 & 15.65 \\
\hline after 3rd day & 45 & 22.72 \\
\hline \multicolumn{3}{|l|}{ Booked } \\
\hline yes & 208 & 99.5 \\
\hline no & I & 0.5 \\
\hline \multicolumn{3}{|l|}{ No of antenatal care } \\
\hline 1 & 3 & $\mathrm{I} .44$ \\
\hline 2 & 12 & 5.77 \\
\hline 3 & 62 & 29.81 \\
\hline 4 and above & $|3|$ & 62.98 \\
\hline \multicolumn{3}{|l|}{$\begin{array}{l}\text { Assisted/attended } \\
\text { during delivery }\end{array}$} \\
\hline yes & 209 & 100 \\
\hline no & 0 & 0 \\
\hline Assisted/attended by & 0 & 0 \\
\hline \multicolumn{3}{|l|}{$\begin{array}{l}\text { TBA traditional birth } \\
\text { attendants }\end{array}$} \\
\hline Health professional & 209 & 100 \\
\hline
\end{tabular}

\section{Prevalence of puerperal sepsis}

This study revealed that $36(17.2 \%)$ had developed puerperal sepsis and most of the study participants had no information about puerperal sepsis (Table 5). 
Table 5 puerperal sepsis among postnatal mothers utilizing postnatal care service at university of Gondar referral hospital, North West Ethiopia, 2017

\begin{tabular}{|c|c|c|}
\hline Variables & Frequency & Percent \\
\hline \multicolumn{3}{|c|}{ puerperal sepsis } \\
\hline yes & 36 & 17.2 \\
\hline no & 173 & 82.8 \\
\hline \multicolumn{3}{|c|}{ Heard about puerperal sepsis } \\
\hline no & 54 & 25.8 \\
\hline yes & 155 & 74.2 \\
\hline
\end{tabular}

\section{Factors associated during logistic regression}

From variables found to be associated with puerperal sepsis during bivariate analysis PROM, mode of delivery, parity and manual removal of placenta were found to be significantly associated with puerperal sepsis during multivariate analysis (Table 6).

Table 6 Bivariate and Multivariate Logistic regression analyses of factors associated with puerperal sepsis among study participants utilizing postnatal care service at university of Gondar referral hospital, January 2017

\begin{tabular}{|c|c|c|c|c|c|}
\hline \multirow[t]{2}{*}{ Variable } & \multicolumn{2}{|c|}{$\begin{array}{l}\text { Puerperal } \\
\text { sepsis }\end{array}$} & \multirow[t]{2}{*}{ COR(95\%CI) } & \multirow[t]{2}{*}{$\operatorname{AOR}(95 \% \mathrm{Cl})$} & \multirow[t]{2}{*}{ P-value } \\
\hline & yes & No & & & \\
\hline \multicolumn{6}{|c|}{ Educational status } \\
\hline $\begin{array}{l}\text { Can't read } \\
\text { and write }\end{array}$ & 7 & 25 & $.33(.09-1.25)$ & & \\
\hline primary & 10 & 49 & $.46(.13-1.56)$ & & \\
\hline secondary & 15 & 56 & $.35(.10-1.12) \mathrm{I}$ & & \\
\hline $\begin{array}{l}\text { above } \\
\text { secondary }\end{array}$ & 4 & 43 & & & \\
\hline \multicolumn{6}{|l|}{ PROM } \\
\hline yes & 4 & 44 & 1 & & \\
\hline no & 32 & 129 & $2.72(.91-8.15)$ & $\begin{array}{l}3.21(1.78- \\
5.21)\end{array}$ & 0.037 \\
\hline \multicolumn{6}{|c|}{ Mode of delivery } \\
\hline SVD & 15 & $\mathrm{III}$ & I & & \\
\hline $\mathrm{c} / \mathrm{s}$ & 21 & 62 & $\begin{array}{l}0.39(0.19- \\
0.83)\end{array}$ & $.98(.18-.82)$ & 0.013 \\
\hline \multicolumn{6}{|c|}{ Shower after delivery } \\
\hline yes & 32 & 166 & I & & \\
\hline no & 4 & 7 & $.33(.09-1.22)$ & & \\
\hline \multicolumn{6}{|l|}{ Parity } \\
\hline $\begin{array}{l}\text { Primiparous } \\
\text { and } \\
\text { multipara }\end{array}$ & 31 & 166 & $\begin{array}{l}3.82(1.14- \\
12.83)\end{array}$ & $\begin{array}{l}3.92(1.10- \\
13.92)\end{array}$ & 0.034 \\
\hline $\begin{array}{l}\text { grand } \\
\text { multipara }\end{array}$ & 5 & 7 & 1 & & \\
\hline \multicolumn{6}{|c|}{ Hypertension } \\
\hline $\begin{array}{l}\text { pre- } \\
\text { eclampsia } \\
\text { eclampsia } \\
\text { and chronic }\end{array}$ & 9 & 24 & $.48(.20-1.15)$ & & \\
\hline chronic & 27 & 149 & & & \\
\hline none & & & $\mathrm{I}$ & & \\
\hline \multicolumn{6}{|c|}{ number of Antenatal care } \\
\hline \multicolumn{6}{|l|}{ I } \\
\hline & I & 2 & $.36(.03-4.16)$ & & \\
\hline 2 & 4 & 8 & $.36(.09-1.31)$ & & \\
\hline 3 & II & 51 & $.83(.37-1.87)$ & & \\
\hline$>=4$ & 20 & 111 & $\mathrm{I}$ & & \\
\hline
\end{tabular}

SVD, spontaneous vaginal delivery; $C / S$, cesarean section; $C C T$, controlled cord traction.

\section{Discussion}

This study has attempted to assess the prevalence of puerperal sepsis among mothers utilizing postnatal care service at University of Gondar referral hospital. It showed that the prevalence of puerperal sepsis was $17.2 \%(95 \% \mathrm{CI} 12.0-22.5)$. The result of this study is in line with the study conducted in Chhainsa village, in in Khyber Agency - Pakistan,(16.2\%), in Gadchiroli district (12.2\%), in Karachi Pakistan (11.2\%)and $11.4 \%$ in Enugu, Nigeria, ${ }^{10,11}$ however higher than the study conducted in Obafemi Awolowo University, Osun State, Nigeria(1.7\%), in Sindh Pakistan (3.89\%), In Liquat University Hospital, Hyderabad, Sindh (6.28\%), In hospitals in Gujarat state, India $3.9 \%$, in BeniSuef Governorate $(1.5 \%) .{ }^{12-15}$ But lower than the descriptive study conducted in Lusaka Zambia (34.8\%) Haryana $\left(20.85 \%\right.$, ) and the study conducted in Bangladesh (34.25\%). ${ }^{11,16}$ The possible reason for the discrepancies in the finding may be due to differences in the data collection place and period. Data collected from the maternity ward and the community will be different from data collected from the postnatal ward. This study was conducted among postnatal mothers utilizing postnatal care service and most of these mothers visit postnatal care when they feel ill or sick and after developing certain signs and symptoms of disease. There is also differences in the duration of data collection among the literatures. Differences in the duration of the data collection probably will result in the different outcomes. Premature rupture of membrane is found to be significantly associated with puerperal sepsis. This is similar with the study conducted in Nigeria, ${ }^{14}$ Black lion hospital Ethiopia ${ }^{17}$ and in Sindh Pakistan. ${ }^{12}$ This could be due to the fact that premature rupture of membrane is a risk for ascending bacterial infection. ${ }^{17}$

Mode of delivery is found to be significantly associated with puerperal sepsis. According to this study those who gave birth by cesarean section was 2 times less likely to develop puerperal sepsis when compared to those who gave birth through spontaneous vaginal delivery. This is inconsistent with the study conducted in Netherlands, California, Scottish and review done by Julia et al. ${ }^{18-20}$ This inconsistency may be due to differences in the setting where data was collected, poor aseptic technique and poor handling of tissue during operation. Cesarean section by itself is not the cause of puerperal sepsis. Most of the mothers participated in this study delivered at University of Gondar referral hospital. The hospital is crowded with a lots of parturient and because it is a teaching hospital, a lots of students are practicing in it. Because there are a lots of students practicing in it, the parturient admitted in the hospital will have repeated vaginal examination which leads to ascending infection which is the risk factors for puerperal sepsis.

This study revealed that low parity (primiparous and multipara) was significantly associated with puerperal sepsis. In this study mothers having less than five children were 4 times more likely to develop puerperal sepsis when compared to those having more than or equal to five children. This is similar with the population-Based retrospective Cohort Study conducted in California, Pakistan and Nigeria. ${ }^{10,19,21}$ The possible reason is young inexperienced mothers are unfamiliar with the process of labour such as the sign of labor, its length and complications. It is mostly primiparous mothers who take a long course of labour and trials in various hands before reaching health facility. This long course of labor can be due to the untested pelvis leads to long course of labour and this exposes them to ascending infection. This is further supported by the study conducted in Kenya. ${ }^{22}$ Another possible reason is that because primiparous are not experienced with labor they fear and go to health institution before the onset of labor and for this they will have frequent vaginal examination which is a risk factors for ascending infection. 
This may be due to lack of previous experience of pregnancy and childbirth whereas multiparas had been experienced obstetric complications which is an important source of their information. Mothers whose their placenta is removed manually is about four times more likely to develop puerperal sepsis than those whose their placenta is removed by controlled cord traction. Consistent with the study conducted in USA. ${ }^{23}$ This could be due to the fact that there is risk of bacterial ascension to endometrial cavity during manual removal of placenta.

\section{Limitation of the study}

There might be a risk of recall bias because women were asked about the events which they faced and health information they heard during their childbirth and postpartum period.

\section{Conclusion}

The prevalence of puerperal sepsis in the postnatal clinic of university of Gondar referral hospital in this study is found to be high. Mode of delivery, parity and mode of placental removal were factors found to be associated with puerperal sepsis.

\section{Declarations}

\section{Ethics approval and consent to participate}

Ethical clearance was obtained from Department of Midwifery, College of Medicine and Health Sciences, University of Gondar institutional review committee. Then individual participants' written consent for participation was obtained.

Consent for publication: as all participant were above 18 years consent for publication was taken from participant.

\section{Availability of data and materials}

The dataset analyzed during the current study available from the corresponding author on reasonable request.

\section{Acknowledgements}

We thanks data collectors and study participants for their cooperation and support during the study period.

\section{Author's contributions}

Daniel Atlaw and Kenbon Seyoum facilitated data collection, analysis, and data interpretation, drafted the final report write up and prepared manuscript. Marta Barta and Demelash Woldeyohannes, participated in developing the tools and data collection process, data analysis and involved in report write up. All authors read and approved the final manuscript.

\section{Conflicts of interest}

We have no conflicts of interests.

\section{Funding details}

There is funding organization for data collection, analysis, and interpretation of data and in writing the manuscript.

\section{References}

1. Dolea C, Stein C. Global burden of maternal sepsis in the year 2000 . 2003.

2. Global health observatory data. Maternal mortality Situation. 2015.

3. Say L, Chou D, Gemmill A, et al. Global causes of maternal death: WHO systematic analysis. Lancet Glob Heal. 2014;2(6):323-333.

4. Abouzahr C. Global burden of maternal death and disability. British Medical Bulletin. 2003;67(1):1-11.

5. Jeroen van Dillena, Joost Zwartb, Joke Schuttec, et al. Department. Maternal Sepsis : Epidemiology , Etiology and Outcome. Lancet Glob Heal. 2017(4).

6. WHO. Education material for teachers of midwifery.

7. Wikipidea. causes of maternal mortality.

8. Curbing Maternal Death in Ethiopia.

9. Duncan ME, Perine PL, Krause DW, et al. Pelvic inflammatory disease and puerperal sepsis in Ethiopia. Am J Obstet Gynecol. 1980;138(7):1-8.

10. Ezugwu FO, Onah HE. Prevalence and Correlates of Maternal Morbidity in Enugu. AJOL. 2010(3):121-130.

11. Oakley L. Prevalence and risk factors of puerperal sepsis in South Asia : a systematic review Supervisor. 2015(3).

12. Khaskheli MN, Baloch S, Sheeba A. Risk factors and complications of puerperal sepsis at a tertiary healthcare centre. Pakistan J Med Sci. 2013;29(4):972-976.

13. Darmstadt GL, Hassan M, Balsara ZP, et al. Impact of Clean Delivery-kit use on Newborn Umbilical Cord and Maternal Puerperal Infections in Egypt. Biomed Centeral. 2009;27(6):746-754.

14. Dare A, Bako CE. Puerperal sepsis : a preventable post- partum complication. Aids Res Hum retroviruses. 2015;15(4):92-95.

15. Madhudas C, Khurshid F, Sirichand P. Maternal Morbidity and Mortality Associated with Puerperal Sepsis. J Liquat Univ Med Heal Sci. 2008;10:121-123.

16. Vallely L, Ahmed Y, Murray SF. Postpartum maternal morbidity requiring hospital admission in Lusaka, Zambia. BMC Pregnancy Childbirth. 2005;8:3-8.

17. Ababa A. Incidence and Determinants of Puerperal Fever among Parturients Who Gave Birth in a Tertiary Teaching Hospital. 2014.

18. Acosta CD, Bhattacharya S, Tuffnell D, et al. Maternal sepsis : a Scottish population-based case - control study. Int J Obstet Gynecol. 2012;1119(4):474-483.

19. Acosta CD, Knight M, Lee HC, et al. The Continuum of Maternal Sepsis Severity: Incidence and Risk Factors in a Population-Based Cohort Study. PLoS One. 2013;8(7):1-8.

20. Hussein J, Ramani KV, Kanguru L, et al. The Effect of Surveillance and Appreciative Inquiry on Puerperal Infections. PLoS One. 2014;9(1).

21. Shamsher S, Rauf B. Puerperal sepsis is still major threat for parturient. $J$ Ayub Med Coll Abbottabad. 2010;22(3):18-22.

22. Maritim Violet. Occurrence and managment of puerperal sepsis. 2012.

23. Panel J, Bowdler E, Dawson J. The association between manual removal of the placenta and postpartum endometritis following vaginal delivery. Obstet Gynecol. 1992;86(6):1002-1006. 